\title{
ANALYSIS OF INVESTMENT ACTIVITIES OF ENTERPRISES OF UKRAINE
}

\author{
Aleskerova Yuliia ${ }^{1}$ \\ Fedoryshyna Lidiia ${ }^{2}$
}

DOI: http://dx.doi.org/10.30525/978-9934-571-28-2_1

\begin{abstract}
The current methods of investment activity, usually aimed at addressing local issues of determining their effectiveness without creating a single mechanism for ensuring reliability under the influence of "risk management" measures. The current mechanism of regulation of investment activity is not yet fully in line with modern requirements and does not have the necessary methodological basis. Also, such issues as regulation of the financial aspect of the investment process of capital reproduction, the formation of resources and sources of investment, the functioning of a fullfledged securities market, etc., have not been worked out.

In modern Ukraine, the notion of investment and investment has become a scientific turning point as a result of the reform of the economy into a market economy. Domestic and foreign economists consider investments as long-term capital investments in various spheres and sectors of the economy, infrastructure, social programs, environmental protection both inside the country and abroad for the purpose of development of production, social sphere, entrepreneurship, and profit.

In conditions of structural adjustment of the Ukrainian economy, the need for large foreign investments is a very acute problem. In most countries (USA, Germany, France, Great Britain), it was the foreign capital that was the catalyst for investment activity, which played an active role in the development and restructuring of the economy. The general state of the economy is significantly influenced by tax legislation, which has a number of shortcomings in Ukraine. Therefore, in the future, it should be foreseen to reduce the tax pressure on production, differentiate tax rates depend-
\end{abstract}

\footnotetext{
${ }^{1}$ Doctor of Economics, Senior Researcher, Associate Professor of the Department of Finance, Banking and Insurance, Vinnitsa National Agrarian University, Ukraine

${ }^{2}$ Candidate of Historical Studies,

Associate Professor of the Department of Analysis and Statistics,

Vinnitsa National Agrarian University, Ukraine

(C) Aleskerova Yuliia, Fedoryshyna Lidiia
} 
ing on the priority of the production sectors, the application of tax breaks (holidays) when taxing profits used to develop production. The costs and profits of enterprises are significantly affected by depreciation rates. The introduction of accelerated depreciation at enterprises would enable them to increase profits in the near future, and hence deductions for investments. International investment activities carried out on financial markets can positively influence the scale and pace of market transformation of national economies, both host and host countries, by developing conditions and factors for their international competitiveness. The analysis of the financial stability of the dairy enterprise by the coefficient of autonomy, the results of which are calculated in the table, allowed to establish such tendencies. The actual values of the autonomy factor in the analyzed period for the enterprise are higher than 2014, than its minimum threshold and have steady growth dynamics. However, since 2014, the company has been tracking a downward trend in this ratio. Accordingly, for these enterprises there is an increase in financial dependence. This indicates a reduction in its potential and a reduction in opportunities for attracting financial resources at the expense of external sources.

\section{Introduction}

In modern Ukrainethe activation of investment activity is particularly important, since without it it is impossible to make progressive changes in the economy, to increase competitiveness and in general, to ensure sustainable socio-economic development of the state.

The current methods of investment activity usually aimed at addressing local issues of determining their effectiveness without creating a single mechanism for ensuring reliability under the influence of "risk management" measures. The current mechanism of regulation of investment activity is not yet fully in line with modern requirements and does not have the necessary methodological basis. Also, such issues as regulation of the financial aspect of the investment process of capital reproduction, the formation of resources and sources of investment, the functioning of a full-fledged securities market, etc., have not been worked out.

The development of investment projects requires consideration of many factors, since external conditions are constantly changing. In assessing an investment project it is necessary to further take into account the risk associated with the temporary value of money especially with the 


\section{Analysis of investment activities of enterprises of Ukraine}

growth of inflation. The return on investment should always be higher than the inflation rate. The correctness and objectivity of such an estimate depends on the timing of return on investment and the prospects of enterprise development. Investing in real projects is a long-term process. Therefore the project must be thoroughly evaluated with maximum consideration of all factors.

The urgency of this topic of work is that our country is in the process of development for which it is necessary to apply attraction of funds from different sources: investment funds, funds of private investors, and especially foreign investments. That is the efficiency of investment activity is one of the first places in the conditions of development of our state.

The purpose of the study is to analyze the investment activity of ROSHEN and justify its improvement.

\section{The concept of investment}

In modern Ukraine the notion of investment and investment has become a scientific turning point as a result of the reform of the economy into a market economy. Domestic and foreign economists consider investments as long-term capital investments in various spheres and sectors of the economy, infrastructure, social programs, environmental protection both inside the country and abroad for the purpose of development of production, social sphere, entrepreneurship, and profit.

The term "investment" comes from the Latin. "Invest", which means "invest". In the broadest sense of the word investment represents a capital investment in order to increase it in the future [4]. Thus, an investment is something that is postponed for tomorrow. One part of them is the consumer goods that are not used in the current period, they are delayed to increase stocks, the other - the resources that are sent to expand production. Investments can be both cash and equities, securities, royalties, movable and immovable property, copyrights.

In terms of finance investments are all types of assets (funds) that are invested in economic activity in order to receive income and from the economic point of view, investments are the costs of creating, enlarging and technical re-equipment of capital.

In modern economic literature the term "investment" is generally interpreted as any investment of funds which can neither lead to capital growth, not to profit. 


\section{Aleskerova Yuliia, Fedoryshyna Lidiia}

These are often referred to as so-called consumer investments that is the purchase of items of long-term use, which in their economic content can not be attributed to investment. It should be borne in mind that investing capital can be carried out not only in cash but also in the forms of movable and immovable property, various financial instruments (securities), intangible assets.

In the Law of Ukraine "On Investment Activity" [3], investments are treated as all types of property and intellectual property that are invested in objects of entrepreneurial activity and other activities that result in the creation of profit (income) or social effect. These values define the law:

- funds, target bank deposits, shares, stocks and other securities;

- movable and immovable property;

- property rights arising from copyright, experience and other intellectual property;

- a set of technical, technological and other knowledge, drawn up in the form of technical documentation, skills and production experience necessary for the organization of one or another type of production, but not patented;

- rights to use land, water, resources, buildings, structures, equipmentas well as other property rights;

- other values.

Foreign experts in the research of the economic content of investments emphasize such factors [6]:

a)growth of functioning capital;

b)obtaining additional income;

c)refusal of a part of the current consumption in favor of the expected expansion of consumption in the future.

Investing is a process of accumulation of funds in different forms (money, stocks, securities, share capital, movable and immovable property, copyrights, etc.), their conversion into investment products and resources, the introduction of the latter into the production stage and the transformation into transforming innovative factors - resources and then in capital [5].

On the basis of the specificity of reproduction of various types of investment resources in today's conditions, there is a need to clarify the classification of investments by individual features.

Particular attention deserves the classification of sources of investment, they are divided into external and internal and they in turn consist of three main blocks. 


\section{Analysis of investment activities of enterprises of Ukraine}

In Ukraine the factors affecting the investment process are in a state that can not contribute to the development of this process. However, world experience suggests that it is impossible to get out of the crisis without increasing the volume of investments.

In conditions of structural adjustment of the Ukrainian economy, the need for large foreign investments is a very acute problem. In most countries (USA, Germany, France, Great Britain), it was the foreign capital that was the catalyst for investment activity, which played an active role in the development and restructuring of the economy. In recent years this trend is particularly characteristic of the economy of the new industrialized countries of Southeast Asia. The volume of direct investment in these relatively small countries in the late 80 -ies exceeded 20 billion dollars USA. In the volume of industrial production in Brazil the share of joint and foreign enterprises in mechanical engineering, metallurgy, chemistry, and petrochemicals is more than $30 \%$. Ukraine should use the experience of these countries (especially the industrialized developed countries of Asia) to attract foreign direct investment on mutually beneficial terms in order to solve the problems of structural transformation, the development of import-substituting industries and consistent expansion of export potential.

According to calculations the total volume of necessary foreign investments in the economy of Ukraine should exceed 40 billion dollars USA, including for metallurgy -7 , machine building -5.1 , transport -3.7 , chemistry and petrochemistry -3.3 billion dollars USA. To date 30 times less money has been invested. Ukraine has potential for effective development of investments in the amount of 2-2.5 billion dollars USA. Such amount will allow to reconstruct the priority industries for 5 years. But annual volumes of foreign investments are 3-7 times less. It should be borne in mind that attraction of foreign investments also requires some expenses. According to calculations for attracting 1 million dollars USA it is necessary to pay an average of 30 thousand dollars USA.

According to experts from the European Center for Research, the entrepreneurial risk of investment in Ukraine is $80 \%$. It is he who causes a small flow of direct investment. According to our calculations, the world's direct investment in the domestic economy accounts for about $1 \%$ or an average of somewhat more than 5 dollars USA per capita.

The general state of the economy is significantly influenced by tax legislation which has a number of shortcomings in Ukraine. Therefore, in the 
future it should be foreseen to reduce the tax pressure on production, differentiate tax rates depending on the priority of the production sectors, the application of tax breaks (holidays) when taxing profits used to develop production.

The costs and profits of enterprises are significantly affected by depreciation rates. The introduction of accelerated depreciation at enterprises would enable them to increase profits in the near future and hence deductions for investments.

Worldwide capital investment is largely carried out in the form of credit resources. However, the banking system of Ukraine does not have the capacity to lend its own producer sufficiently. This is due to the lack of a system of credit risk insurance and bank deposits.

With the insurance system you can significantly increase the source of investment such as saving the population. In Ukraine the population saves its savings in freely convertible currency. Despite the relatively low level of current consumption, some estimates suggest that these savings amount to 10 billion dollars USA. If you create the appropriate conditions these funds would work for the development of the economy.

\section{Characteristics of the investment project Roshen}

PJSC "Bershadmoloko" is a milk processing enterprise which is located in the village Florin Bershad district of Vinnytsia region.

The plant is the main provider of dairy products for Roshen sweets. The capacity of the plant is to process up to 320 tons of milk per day. The plant is among the top ten producer leaders in Ukraine, as the largest dairy processor. Bershadmoloko can produce more than 20 tons of dry dairy products: 18 tons of skimmed milk powder, 24 tons of dry cream, 22 tons of whole wheat milk, over 40 tons of condensed milk and about 10 tons of cream butter per day.

PJSC "Bershadmoloko" conducts its activity exclusively at the expense of own funds on the basis of self-financing and self-sustainment has enough own working capital.

At present the competitive development of PJSC "Bershadmoloko", its profitability and large volumes of sales is provided by Roshen Corporation, as the dairy factory is the main supplier of dry milk for the confectionery giant. Competitive positions of the enterprise are kept at the expense of economy of expenses, productivity, rational use of fixed assets, provision 
of material and technical resources, technological components, price and sales levers. However, the following components of the competitive development of the enterprise, such as the uniqueness of products and the ecological image, should be mentioned separately.First of all it applies to products such as condensed milk that is in demand on the market, which provides the plant with high volumes of sales. PJSC "Bershadmoloko" began to produce this product for the needs of the confectionery corporation "Roshen" and each year, this product is growing demand. The famous enterprise has such unique products as dry whole milk and extra cream "Extra" which are used by confectionery enterprises of our state for the production of milk and white chocolate.Milk at PJSC "Bershadmoloko" passes three stages of control systems in several laboratories equipped with modern technology. Dairy raw materials are taken to the plant according to indicators that are much tougher than domestic requirements than required by the state standard. In the 2013 season Bershadmoloko achieved production of dry extra cream "Extra" in the amount of 300 tons per month, and began with 70-80 tons. Another competitive and unique product of PJSC "Bershadmoloko" is buttermilk, which is used for the production of cakes, therefore the "Kiev Cake" produced by "Roshen" has unmatched taste qualities and is well known far beyond Ukraine.

Sustainable competitive position of the leader of the dairy industry of Vinnytsia and Ukraine, all this primarily due to the constant and guaranteed market for the sale of its own products, which provides for Roshen Corporation, which owns $86 \%$ of the shares of PJSC "Bershadmoloko", for the PJSC "Bershadmoloko". Due to the fact that the main customer of products - Roshen corporation - Bershadmoloko company works at full capacity and increases the production of its products, which is high quality and competitive. One of the decisive preconditions for such a level of competitive development of the enterprise was the fact that in the case of PJSC "Bershadmoloko" and the producer and the seller are interested in increasing profits, there are marketing mechanisms for managing the activities of the enterprise, introduced by the owners.

The Supervisory Board of PJSC "Bershadmoloko" in 2013 decided to transfer the production capacities (in part) to the city of Vinnitsa and the creation of PJSCVinnitskydairy plant Roshen. In 2014 the company has already started to produce dairy products. After analyzing the enterprise we can conclude that the largest share of the structure of available financial 


\section{Aleskerova Yuliia, Fedoryshyna Lidiia}

resources is occupied by stable liabilities and other current liabilities. When they are at the disposal of the company before their use they can be used to finance expanded reproduction.

An important source of financial resources are depreciation, they remain in the enterprise and should be used for renewal in fixed assets. The amount of depreciation deductions during this period is almost unchanged: $2011-1.14 ; 2012-1,40 ; 2013-1.29 ; 2014-0.98$.

PJSC "Bershadmoloko" demonstrates stable growth of own capital. It was noted that the value of the invested capital (statutory + additional) at the specified enterprise did not increase. In general the growth of equity capital was due to the resulting retained earnings and accumulated capital. The size of the reserve capital has not changed during the investigated period, which indicates the stability of the operation of the enterprise, the absence of additional emissions.

Due to the transfer of separate production facilities to the newly created milk processing enterprise in the city of Vinnytsia in 2014 and 2015 PJSC "Bershadmoloko" suffered losses.

Efficient use of capital at the enterprise contributes to profitability at the enterprise. As can be seen from the data in table 1 the indicator of profitability of products in all societies tends to increase, which indicates an increase in the ability to turn profit into profit.

Table 1

Analysis of profitability of enterprises in terms of profitability

\begin{tabular}{|c|c|c|c|c|c|c|c|c|c|}
\hline \multirow[b]{2}{*}{ Enterprise } & \multicolumn{3}{|c|}{2011} & \multicolumn{3}{|c|}{2012} & \multicolumn{3}{|c|}{2013} \\
\hline & 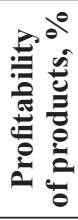 & 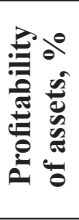 & 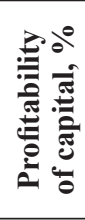 & 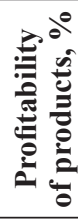 & 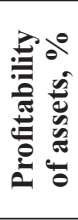 & 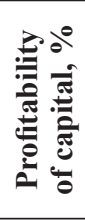 & 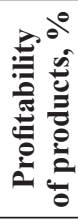 & 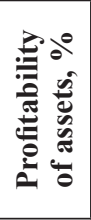 & 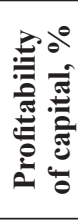 \\
\hline $\begin{array}{l}\text { PJSC } \\
\text { "Bershadmoloko" }\end{array}$ & 6,3 & 29,4 & 37,97 & 9,7 & 25,7 & 33,55 & 9,26 & 21,79 & 25,33 \\
\hline
\end{tabular}

Also, we note that the enterprise on the main indicators during the investigated period worked profitable. Thus, PJSC "Bershadmoloko" worked profitable for 2011-2013, but the level of these indicators fell every year and at the end of the period fluctuated within $3-4 \%$. 


\section{Increase of production capacities at the expense of capital investments of PJSC "Bershadmoloko"}

An increase in capital investment is a prerequisite for the growth of production capacity on a new technological basis and accordingly, an increase in labor productivity.

Table 2

Dynamics of capital investments of PJSC "Bershadmoloko" (PJSC Vinnytsia Dairy Plant "Roshen") for 2011-2016

\begin{tabular}{|l|c|c|c|c|c|c|c|}
\hline $\begin{array}{c}\text { Name of } \\
\text { Company }\end{array}$ & $\mathbf{2 0 1 1}$ & $\mathbf{2 0 1 2}$ & $\mathbf{2 0 1 3}$ & $\mathbf{2 0 1 4}$ & $\mathbf{2 0 1 5}$ & $\mathbf{2 0 1 6}$ & $\begin{array}{c}\text { Absolute } \\
\text { deviation } \\
(+;-)\end{array}$ \\
\hline $\begin{array}{l}\text { PJSC } \\
\text { "Bershadmoloko" }\end{array}$ & 6617 & 6303 & 6070 & 8941 & 11810 & 16580 & +9963 \\
\hline
\end{tabular}

In analyzing the dynamics of capital investment for a dairy enterprise, which is reflected in the "Notes to the Annual Financial Statements", Section III "Capital Investments", it should be noted that for the period 2011-2016 the company invested in capital investments, gradually increasing the amount of investment. Worldwide practice shows that capital investment needs to be continuously optimized, as in a changing global economy, this instrument will generate a sustained loss and the ability to sell assets at fair value will be low.

The bulk of the capital investments of PJSC "Bershadmoloko" is aimed at the acquisition (creation) of intangible assets and fixed assets. According to the annual accounts, the company actively procured technological equipment. This will further enable enterprises to improve the quality of finished products and to make full use of raw materials. Thus, during the investigated period, the volume of commissioning of the active part of fixed assets increased 3.5 times, and the average annual value of fixed assets increased 4 times.Accordingly, the refinancing factor for this stage increased and in 2016 it was $0.17 \%$. It should be noted that $75 \%$ of capital investment was used to purchase (create) intangible assets - rights to use property and industrial property.

The main source of capital investment for enterprises is net profit. Profit is the most important criterion for any entrepreneurial activity and the most important source of accumulation, expanded production. 
The investigated dairy business has had very different financial results over the last five years. But even with loss-making activity (2015), they made investments. This situation suggests that these companies are at risk, which will further have an economic effect.

Obviously, investment activity is inextricably linked with innovation, because the creation of an innovative product is a process that requires a lot of time and money, that is, investment. The successful functioning of dairy enterprises and the achievement of strategic advantages in a competitive environment depends to a large extent on the financing of their innovation activities. According to the State Statistics Committee of Ukraine, dairy processing enterprises of Ukraine for 2011-2016 have increased the volume of investments in fixed assets by 1.5 times, while the volume of investment in innovation has increased by 1.2 times.Funding for innovations is carried out mainly at the expense of own funds, the share of which is on average $80 \%$ of the total investment in innovation. During the investigated period also there was a positive dynamics of financing of innovations at the expense of loans, the annual growth of which is an average of $10 \%$.

Studies have shown that the main areas of innovation in dairy processing enterprises are first of all technological innovations.

Roshen Corporation creates its own developed integrated structure investing resources in the development of its own business. PJSC Vinnytsia Dairy Plant Roshen uses milk from the "Litinsky Plemise Plant" LLC and the "Ukrayina" agricultural company which is part of the corporation, avoiding production risks (supply and quality of raw materials). Finished products (butter, milk powder) are sold to the confectionery factory "ROSHEN". Such integration ties increase the profitability of the participants in the integration since production is carried out from its own raw materials, bypassing the intermediaries. Such vertical integration contributes to the development of the enterprise.

Net profit is one of the most important economic indicators contributing to investment activity. Quantitativelyit represents the difference between the amount of profit before tax and the amount of taxes paid in the budget from profits, economic sanctions and other mandatory payments of the enterprise which are covered by profit.

The final financial result of the investigated milk processing enterprise is characterized by a gradual decrease in losses before the formation of net profit in 2012-2016. 
Studies show that depending on which criteria of effectiveness are chosen as the basis for this organization the conclusions can be made diametrically opposite. Even with regard to a single project the decision to accept it is not always obvious, since the choice of a particular criterion may, under certain conditions, justify one or another solution. The situation is sharply complicated if you have to evaluate several projects, and those that are in different interdependencies.Contradictions arise between the criteria of different groups - based on discounted and undiscounted estimatesbut even in the intuitive level it can be assumed that such differences may arise among groups of homogeneous criteria.

Thus, the main conclusion is that, from all the criteria considered the criteria for NPV, IRR and $\mathrm{Pl}$ are the most acceptable for making investment decisions. Despite the interconnection between these indicators when evaluating alternative investment projects, the problem of choosing a criterion remains. The main reason for this lies in the fact that NPV is an absolute index, while Pl i IRR is relative.

When making a decision, one should be guided by the following considerations:

a) choose an option with a higher NPV, since this indicator characterizes the potential increase in the economic potential of the organization (increasing the economic strength of the enterprise is one of the most important guidelines);

b) it is also possible to calculate the IRR for indicators of growth of capital investments and incomes; with IRR $>\mathrm{CC}$, then the incremental costs are justified and it is advisable to accept the project with larger capital investments.

Consequently, after identifying the main problems in assessing the reliability of investment projects we see that there is no single defined evaluation system that complicates the adoption of an investment decision.

The transition to a new model of Ukraine's economic development makes the research of new approaches to the management of investment activities of industrial enterprises, especially those that are still in a crisis situation is particularly relevant.

Current methods of evaluating investment projects are usually aimed at solving local issues of determining their effectiveness without creating a single mechanism for ensuring reliability under the influence of "risk management" measures.At the same time existing developments require a deeper consideration of the degree of risk in investment calculations, further 


\section{Aleskerova Yuliia, Fedoryshyna Lidiia}

development in the direction of forming an integral system of reliability, improvement of methodological approaches to determining the investment characteristics of the project, the process of risk management and optimization of its consequences, which is a prerequisite for the creation of a comprehensive effective economic the mechanism of ensuring the reliability of the investment project.Systemic consideration of the ways and suggestions for significant acceleration and increase of efficiency of investment activity allows to group them around the following main problems:

- Creation of an investment-friendly environment for investors;

- Identification of state, sectoral and regional priorities;

- Formation of an integrated system of public management of investment activities;

- Consolidation and development of sources of investment financing;

- Creation of a system of state support of investment activity of branches, territories, economic entities and investment projects.

In order to increase the efficiency of investment activity in Ukraine it is expedient:

a) to develop support for domestic producers, competitive products, export and displacement from the Ukrainian market of imported goods;

b) to work out mechanisms for the establishment and realization of investment priorities;

c) develop and comprehensively use all possible sources of investment attraction, both domestic and foreign;

d) to implement effective state depreciation policy which would ensure tangible accumulation of investment funds and accelerated updating of the capital stock of the enterprise of all forms of ownership;

e) to restore and implement an effective system of state examination of investment projects, providing state support for priority projects;

f) to introduce mechanisms of guaranteeing and insurance of all kinds of investments from possible risks;

g) to actively use the investment potential of the regions of Ukraine, ensuring their orientation to the implementation of national priorities;

h) to broadly study and implement a positive experience of investing in the economies of the CIS and foreign countries.

In order to intensify investment activity necessary conditions should be created in which positive factors of influence and growth of the internal investment potential of enterprises, industries and regions will operate. To 
do this it is necessary to overcome the non-payment crisis, strengthen the financial and credit sphere, and create conditions for the effective operation of privatized enterprises. In the absence of these conditions the state investment policy will solve only the current tasks of socio-economic survival of the country and the population, and will not create conditions for activation of investment processes.

In order to improve the state of investment environment in Ukraine, institutions of state power need to be strengthened: to improve the legislation, to work effectively the courts, to eliminate crime and corruption. This work should be carried out in parallel with exceptionally important structural shifts - equalization of the conditions of competition and further liberalization of the economy. Inefficient enterprises should not be supported by the state and the local administration either directly or indirectly. There is an acute need to create a complete investment infrastructure, primarily distribution and accumulation systems (banks, insurance companies, mutual funds and pension funds, stock market, in relation to). Investors should be able to reduce or eliminate risks through generally accepted financial and legal instruments in world practice.

Consequently, the main purpose of investment activity management is to determine the directions, methods, means and forms of investment in order to increase the efficiency of production and increase the profit of the enterprise.

\section{Findings}

Based on the experience of the Czech Republic in our opinion in Ukraine it would also be advisable to create an organization that would negotiate internationally with potential investors regarding the placement of their enterprises and service centers in Ukraine and cooperated with local communities in preparing their specialists and territories for work with such investors. It is also appropriate in each regional center of Ukraine to create branches of this organization which would ensure the coordination of activities with local authorities, regional agencies, construction and design companies, universities and educational institutions.

As in the Czech Republic, in Ukraine, such a network would help to respond promptly to requests and investment proposals of foreign companies, offer them several alternative locations for the placement of their productions, and accompany them throughout the entire business start-up process. 
It should be noted that the largest capital was invested by foreign investors in production activities $(42.5 \%)$, in the financial and banking sector (22.7\%), transport and communications $(12.2 \%)$, trade and repair $(8,7 \%)$, construction $(5.4 \%)$, services $(3.5 \%)$, energy, gas and water supply $(2.3 \%)$, hotels and restaurants (1.5\%) [2].

Foreign investors are convinced that the biggest obstacles to investing in Ukraine are large-scale corruption (an average score of 8.5 points out of 10 possible) and lack of trust in the judiciary (7.5 points). The military conflict with Russia (6.1 points), as well as the unpredictable exchange rate and the unstable financial system ( 6 points) rank third.

Broad-mass corruption and lack of trust in the judiciary are the first and second place for all investor groups: portfolio and strategic, those who have already invested in Ukraine and those who have not dared to do so. Interestingly for the investors who are actively seeking opportunities to conduct business in Ukraine the existing military conflict is one of the least significant obstacles - they put it 7 th place ( 4.9 points). Instead the top three obstacles in addition to corruption and the judicial system for this group are complex tax administration (6.1 points).

As to the actions to be taken by the Ukrainian authorities to attract foreign investment the priority tasks of investors are to restart the judicial system by testing existing ones and attracting new judges (an average score of 7.6 points out of 10 possible), as well as bringing to justice a large number Senior Officials and Judges for Corruption (7.4 points). At the same time, the third step in rating the important actions of the government are such actions as ensuring the further timely implementation of the IMF program, the liberalization of currency control (including the lifting of the ban on repatriation of dividends) - by 6.2 points.

On the initiative of local authorities there are areas of active management. They are being modified and aimed at strengthening entrepreneurship in the region. Attractive investors offering them in the first place benefits from taxation and local payments, land rent (on preferential grounds) with the possibility of its redemption.

It is also important for Ukraine to use a certain foreign experience of business incubation on the basis of large enterprises.

For example in Sweden the type of incubator, the so-called "internal" incubator, which is created by large enterprises to stimulate new ideas and projects is common. Although some projects can be implemented within a 


\section{Analysis of investment activities of enterprises of Ukraine}

large enterprise, most of them are separated from it especially in those cases where the business project is not related to the main direction of the large enterprise [2].

In Finland an incubator in the business center in the southwest of Khayma covering an area of 1,750 square meters, setting itself the task of creating jobs in the processing industry by establishing links between industrial enterprises and educational institutions.

The incubator collaborates with a local technical college as well as with universities and research institutes in the southern and central parts of Finland. The business clients of this business incubator created half the jobs in the local electronics industry. As for other business incubators, their cooperation with existing companies is important: incubators contribute to the formation of new services and subcontracting in the region. Mostly they are based on a specific industrial sector.

Although incubators create few new businesses as compared to their total number, they play an important role in targeting and stimulating the development of innovative business, reforming local business structures and service systems.

The practice of functioning of innovative investment structures in Norway is rather interesting and peculiar. The Oslo Economic Development Agency employs 100 people, of which 35 are the administration and business development department.

The main task of the department of business development is to facilitate the opening of as many new enterprises as possible. The agency's principle of operation is "one stop shop", that is the provision in one place of a complete package of information and documentation for the opening of the firm. In addition to the Municipal Agency, there are six other business incubators operating in Oslo [1].

Now let's turn to the practice of the Business Incubator of the Innovation Technopark in the Hedmark region (Hamer, Norway). The city of Hamer is the center of the 85,000th Hedmark region. The local budget of the city is NOK 1.5 billion.

The industrial park includes an industrial cluster and a business incubator, and the main areas of work of the technopark are bio-industries as well as bio- and computer technologies.

The aim of the technopark is the economic growth of the Hedmark region. Today the technopark receives investment from the state-owned 
Norwegian Innovation Corporation and Norwegian Banks, while 25\% of the incubator is owned by the Hamer municipality. The Technopark is part of the State Corporation for Industrial Growth.

It should be noted that the above-mentioned practices of creating different centers of innovation are already beginning to be applied in Ukraine and are of great importance for strengthening the European integration of Ukrainian cities.

\section{Conclusions}

Based on the results of the research we can conclude that the investment project is a complex development which presents the maximum amount of information about the source of investment, taking into account all external and internal factors of influence, the amount of expected income and the timing of the project.

Having considered the various methods of evaluating investment projects we can say that one chosen method can not be used to evaluate all projects because it will characterize only one project indicator which is inappropriate. Some methods have malfunctions on a mathematical basis, therefore, it is necessary to apply several methods for assessing projects, which will make it possible to more realistically assess the feasibility of investing in a particular project.

Studies have shown that the main areas of innovation in dairy processing enterprises are first of all technological innovations.

The analysis of the financial stability of the dairy enterprise by the coefficient of autonomy, the results of which are calculated in the table, allowed to establish such tendencies. The actual values of the autonomy factor in the analyzed period for the enterprise are higher than 2014, than its minimum threshold and have steady growth dynamics. However, since 2014, the company has been tracking a downward trend in this ratio. Accordingly for these enterprises there is an increase in financial dependence. This indicates a reduction in its potential and a reduction in opportunities for attracting financial resources at the expense of external sources.

Having considered the main problems in making investment decisions we see there is no single system for evaluating investment projects. We also saw that the project was evaluated by different methodsshowing different results. That is, evaluation of the project only by calculation is unacceptable. 
In the formation of the cash flow of the project and therefore, its factors are involved in the positive (profitable) and negative (costly) nature. That is, the expected cash receipts identified in the project can vary significantly when changing external or internal conditions.

Therefore, it is important to evaluate it as precisely as possible before adopting a particular investment project, to determine the minimum profit from it, provided that there is a risk situation and if necessary involve a co-investor in order to guarantee proper project implementation.

It should be noted that today in Ukraine there is a fragmented and underdeveloped market of investment resources. Organizations working on it operate inadequately coordinated and inefficient. The weak development of the information infrastructure of the market has become an obstacle to active actions of domestic entrepreneurs and potential investors.

\section{References:}

1. Abramovich I.V. (2007) Investuvannya $\mathrm{v}$ agrarniy sektor ekonomiki Ukrayni: problemi ta napryami ïkh virishennya. Derzhava ta regioni. Seriya: Ekonomika ta pidpriymnitstvo, № 1, p. 7-9.

2. Investitsiyna analitika. [Elektronniy resurs]. - Rezhim dostupu: http://www.inventure.com.ua

3. Kiryan S.M., Radchenko O.D. (2006) Model' obliku investitsiy dlya malikh sil's'kogospodars'kikh pidpriymstv. Agrarniy forum - 2006, № 9, p. 235.

4. Koyuda V.O., Lepeyko T.I., Koyuda O.P. (2011) Osnovi investitsiynogo menedzhmentu. K. : Kondor, p. 165-181.

5. Ladichenko N. (2007) Otsinka finansovikh investitsiy. Bukhgalteriya, № 27/1(442), p. 64.

6. Len' V.S., Glivenko V.V. (2008) Bukhgalters'kiy oblik v Ukrayni: osnovi ta praktika: 3-te vidannya. navch. pos., K.: TsUL, 608 p. 